This item was submitted to Loughborough's Research Repository by the author.

Items in Figshare are protected by copyright, with all rights reserved, unless otherwise indicated.

\title{
A Tesla-pulse forming line-plasma opening switch pulsed power generator
}

PLEASE CITE THE PUBLISHED VERSION

http://dx.doi.org/10.1063/1.3484193

\section{PUBLISHER}

(C) American Institute of Physics

\section{VERSION}

VoR (Version of Record)

\section{LICENCE}

CC BY-NC-ND 4.0

\section{REPOSITORY RECORD}

Novac, Bucur M., Rajesh Kumar, and Ivor R. Smith. 2019. "A Tesla-pulse Forming Line-plasma Opening Switch Pulsed Power Generator”. figshare. https://hdl.handle.net/2134/7244. 
This item was submitted to Loughborough's Institutional Repository (https://dspace.lboro.ac.uk/) by the author and is made available under the following Creative Commons Licence conditions.

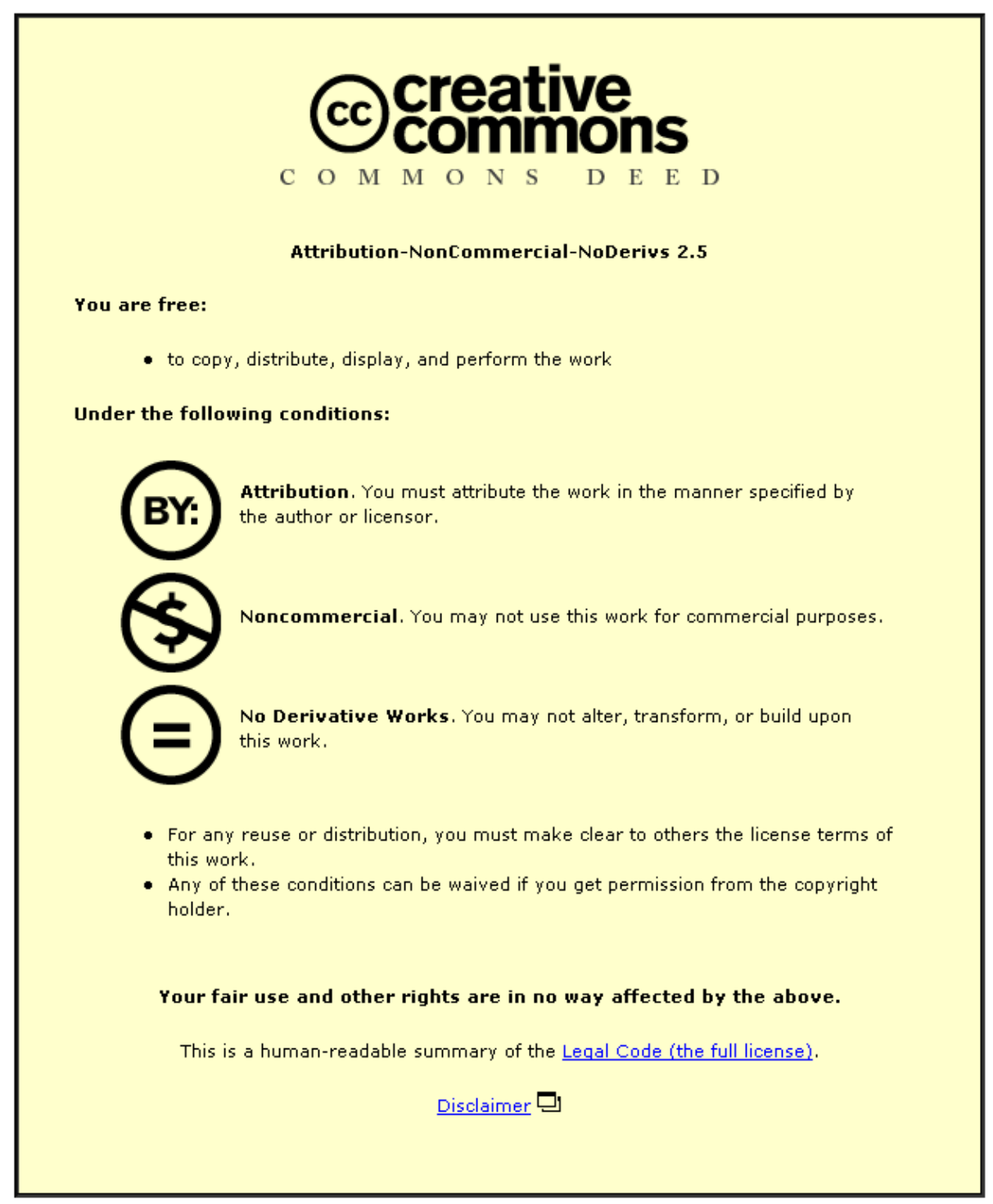

For the full text of this licence, please go to: http://creativecommons.org/licenses/by-nc-nd/2.5/ 


\title{
A Tesla-pulse forming line-plasma opening switch pulsed power generator
}

\author{
B. M. Novac, R. Kumar, and I. R. Smith \\ Department of Electronic and Electrical Engineering, Loughborough University, Loughborough, \\ Leicestershire LE11 3TU, United Kingdom
}

(Received 3 July 2010; accepted 7 August 2010; published online 22 October 2010)

\begin{abstract}
A pulsed power generator based on a high-voltage Tesla transformer which charges a $3.85 \Omega / 55 \mathrm{~ns}$ water-filled pulse forming line to $300 \mathrm{kV}$ has been developed at Loughborough University as a training tool for pulsed power students. The generator uses all forms of insulation specific to pulsed power technology, liquid (oil and water), gas $\left(\mathrm{SF}_{6}\right)$, and magnetic insulation in vacuum, and a number of fast voltage and current sensors are implemented for diagnostic purposes. A miniature (centimeter-size) plasma opening switch has recently been coupled to the output of the pulse forming line, with the overall system comprising the first phase of a program aimed at the development of a novel repetitive, table-top generator capable of producing $15 \mathrm{GW}$ pulses for high power microwave loads. Technical details of all the generator components and the main experimental results obtained during the program and demonstrations of their performance are presented in the paper, together with a description of the various diagnostic tools involved. In particular, it is shown that the miniature plasma opening switch is capable of reducing the rise time of the input current while significantly increasing the load power. Future plans are outlined in the conclusions. () 2010 American Institute of Physics. [doi:10.1063/1.3484193]
\end{abstract}

\section{INTRODUCTION}

A broad range of modern industrial applications, from the intense microwave and UWB sources used in defense systems to the generators needed for food sterilization and industrial pollution control, all require compact and repetitive pulsed power supplies able to provide gigawatts of output power. Although the Marx generator is a straightforward possibility, it certainly does not provide either the simplest or the most compact source at this level of power. Loughborough has a long tradition of building and implementing compact Tesla-based generators for various applications ${ }^{1,2}$ and it has been demonstrated that under certain conditions a Tesla transformer-based system provides a better solution than one using a Marx generator. In most situations the transformer is used to charge a pulse forming line (PFL), which in turn is discharged to a load via a high-voltage closing switch, thereby conditioning the output pulse and increasing the power delivered.

As the demand for the level of power increases to well over $10 \mathrm{GW}$, the use of a plasma opening switch (POS) as a second stage of pulse compression becomes very useful. The POS operates in vacuum, requires only a small cold plasma source, and relies on magnetic insulation to withstand high output voltages ranging from a few hundred kilovolts to a few megavolts. The POS two-electrode geometry is usually coaxial-cylindrical, with the load attached at one end and the input power generator at the other. Once the current injected into the POS reaches a critical level, the switch opens in a time much shorter than the rise time of the input current, and a greatly increased power is transferred to the load. ${ }^{3}$ The POS was developed initially for very high-current applications (hundreds of kiloamperes up to a few mega-amperes) and considerable effort was expended in developing large units capable of fast opening under input currents with rise times ranging from hundreds of nanoseconds to $1 \mu \mathrm{s}$. However, as the first reported experiments ${ }^{4}$ established, the POS is capable of opening currents having much shorter rise times (i.e., tens of nanoseconds) and, under optimum conditions, of generating a load current having a rise time about ten times shorter than that of the input current. The aim of the experiments described was threefold: to demonstrate that a POS can indeed be miniaturized down to centimeter size, used at a current level of just a few tens of kiloampere, and still provide power amplification.

Although it is anticipated that eventually semiconductor based opening switches will become capable of handling tens of gigawatts, and although in principle this is already possible, the result will be extremely bulky, very heavy, and prohibitively expensive. For high power generation at the present level of technology, the only practical solution for a compact and repetitive opening switch is the POS, even though an auxiliary energy source is required for the production of plasma. It is a long-term goal of the Loughborough Pulsed Power Group to develop a table-top repetitive POSbased generator, capable of producing an output well in excess of $10 \mathrm{GW}$. Once this is achieved, the same technology can be adopted in much larger and more powerful systems by the use of a modular approach.

This paper presents firstly the development of a multigigawatt Tesla transformer-based PFL generator, together with the associated diagnostic equipment. Secondly, a miniature POS is described, together with its own dedicated plasma gun source. Plasma diagnostic experiments are also mentioned, using Faraday cup sensors and an ultrahigh-speed camera. Results obtained from the complete Tesla-PFL-POS system, coupled to a dynamic load represented by a diode, 


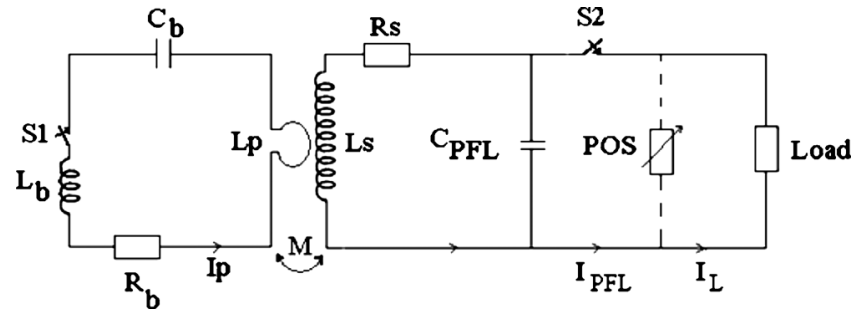

FIG. 1. Equivalent electrical circuit for the Tesla-PFL-POS generator. Subscripts $b, p$, and $s$ are for the capacitor bank and the Tesla transformer primary and secondary circuits; $L$ is for the load. S1 and S2 are closing switches and $C_{\mathrm{PFL}}$ is the PFL capacitance.

are then presented and briefly discussed. Finally, future plans related to the development of a table-top system are mentioned.

\section{300 KV TESLA TRANSFORMER-CHARGED PFL GENERATOR}

\section{A. Tesla transformer}

Figure 1 shows the electrical arrangement of the overall Tesla-PFL-POS assembly. The detailed design of the Tesla transformer used the Loughborough 2D filamentary model, ${ }^{5,6}$ which accounts for magnetic diffusion, skin and proximity effects, and even the influence of metallic components located in the vicinity, such as the PFL. The capacitance of the multiturn secondary winding was calculated using a two-step process. First, the coil was considered as simply a collection of metallic rings and using ANSOFT software ${ }^{7}$ the matrix of Maxwell (capacitance and self-capacitance) coefficients was obtained. This was followed by a numerical technique, similar to that in Ref. 8.

The capacitor bank $C_{b}$ of Fig. 1 consists of three parallel-connected $30 \mathrm{kV}$ capacitors (GAEP type 31151) (Ref. 9) with a combined capacitance of $1.83 \mu \mathrm{F}$ which, together with a short parallel-plate transmission line, comprises the power source for the system. Normal operation is at $25 \mathrm{kV}$ and, to keep within the $25 \mathrm{kA}$ safe working current of each capacitor, the charging voltage is restricted to $27 \mathrm{kV}$. A low-inductance trigatron S1 (L-3 Sciences type T-670), ${ }^{10}$ operating in compressed air and triggered by a $60 \mathrm{kV}$ voltage impulse from a TG-70 trigger generator (L-3 Sciences), ${ }^{10}$ closes the primary circuit of the Tesla transformer, with the effective resistance and inductance of the circuit being $R_{b}$ $=56 \mathrm{~m} \Omega$ and $L_{b}=79 \mathrm{nH}$. The primary winding [Fig. 2(a)], which has a self-inductance $L_{p}$ of $165 \mathrm{nH}$, is a single-turn of $100 \mu \mathrm{m}, 236 \mathrm{~mm}$ wide copper sheet wrapped around a 240 $\mathrm{mm}$ diameter plastic mandrel and sandwiched between layers of Mylar-polyethylene using heat-enabled encapsulation for air removal.

The voltage of the capacitor bank is measured by means of a North Star $100 \mathrm{kV}$ 1:2000 voltage divider and the primary current $I_{p}$ by integrating the time rate-of-change of the output of a B-dot probe, calibrated in situ and located in a tunnel in the ground plate of the short transmission line connecting the bank to the primary winding of the transformer. To remove any possible capacitive coupling, the magnetic probe is shielded by a thin slotted copper tube sheet connected to the ground plate of the transmission line. To con-

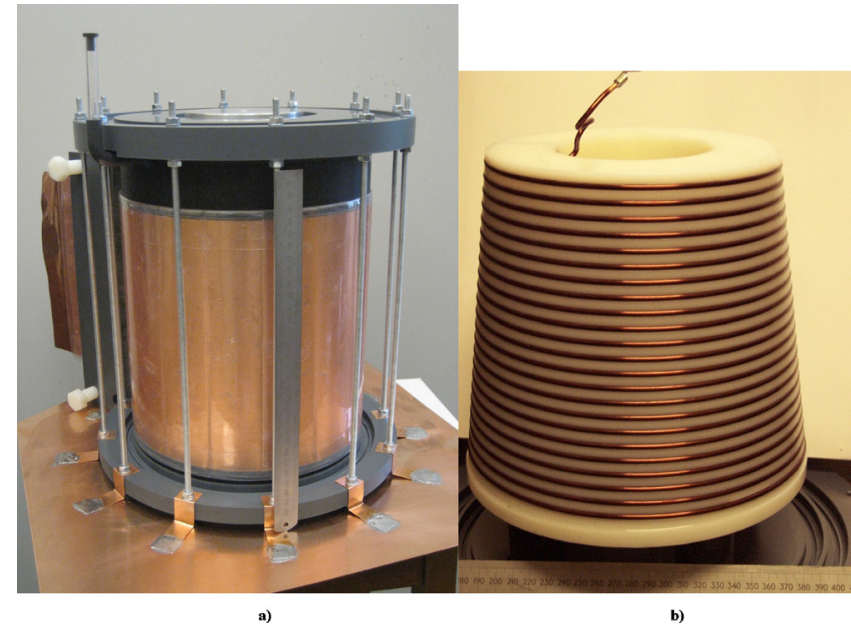

FIG. 2. (Color online) Tesla transformer: (a) primary winding and (b) secondary winding.

firm the calculated parameters, the primary circuit was separately tested, with the results obtained being extremely close to theoretical predictions.

The secondary 23 turn constant pitch secondary winding of the Tesla transformer [Fig. 2(b)] is of $3 \mathrm{~mm}$ diameter enameled copper wire, wound on a conical polyethylene former with a largest diameter of $209 \mathrm{~mm}$, a smallest diameter of $131 \mathrm{~mm}$ and a height of $178 \mathrm{~mm}$. The calculated self-inductance $L_{s}$ and capacitance $C_{s}$ were $62.3 \mu \mathrm{H}$ and 70 $\mathrm{pF}$. A relatively high resistance $R_{s}$ of $1.1 \Omega$ is effective during operation, when significant skin and proximity effects increase the dc resistance by about 6.5 times. Because of the high secondary voltage the transformer, operating at a resonant frequency of about $238 \mathrm{kHz}$ is immersed in oil, with the calculated primary/secondary mutual inductance $M$ being

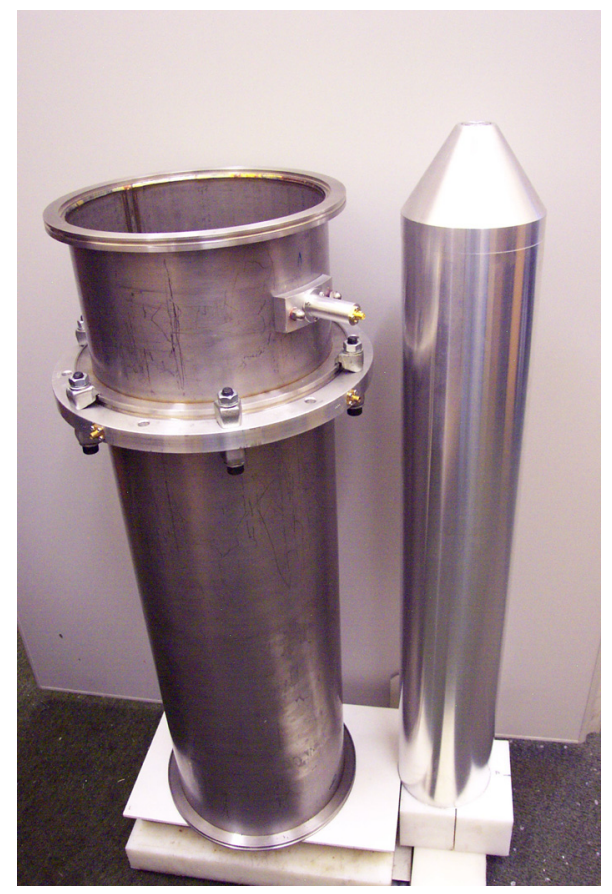

FIG. 3. (Color online) Main components of PFL. The V-dot sensor can be seen attached to the external PFL wall. 


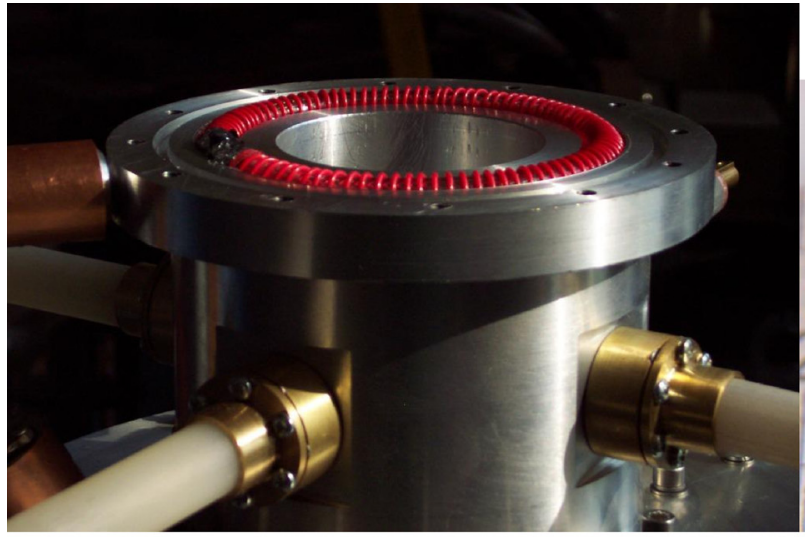

a)

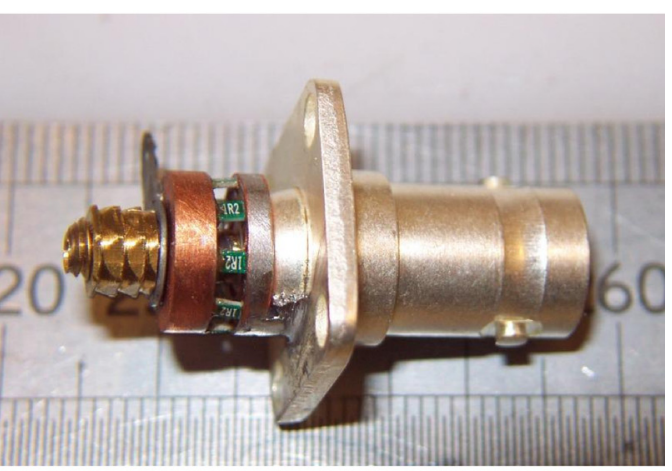

b)

FIG. 4. (Color online) Self-integrating Rogowski coils (a) one of the two coils mounted inside the vacuum chamber wall (note the four plasma gun cables, part of the POS) (b) very low-inductance CVR used at the output of each coil, mounted on a BNC panel connector.

$2.1 \mu \mathrm{H}$. The corresponding coupling coefficient $k$ of 0.65 , obtained by mounting the two windings with an axial offset of $80 \mathrm{~mm}$, is sufficiently close to the 0.6 value required for the design of a dual-resonant Tesla transformer.

\section{B. Pulse forming line}

During normal operation the Tesla transformer charges a $3.85 \Omega / 55$ ns water-filled PFL to $300 \mathrm{kV}$. The PFL has an outer diameter of $247 \mathrm{~mm}$, an inner diameter of $140 \mathrm{~mm}$, an axial length of $933 \mathrm{~mm}$, and an equivalent capacitance $C_{\mathrm{PFL}}$ of about $7 \mathrm{nF}$, with the main components being shown in Fig. 3. Using a pump and a two-stage filter the resistivity of the circulated water is maintained in excess of $15 \mathrm{M} \Omega \mathrm{cm}$. The Tesla transformer output voltage, i.e., the PFL charging voltage, is monitored by a V-dot sensor (see Fig. 3) designed following Ref. 11 and mounted in the thick stainless steel metal wall of the PFL, very close to its output.

Identical Rogowski coils [Fig. 4(a)] monitor the output currents of the PFL and the POS, i.e., the load current in the vacuum chamber. Both probes are constructed according to established techniques ${ }^{12}$ and have rise and droop times of 1 ns and $2 \mu \mathrm{s}$, respectively. The most challenging part of the current sensor is the very low-inductance of the current viewing resistor (CVR), which is required to be at most a few hundreds of picohenrys. As the arrangement of Ref. 13 was difficult to implement, a novel solution for the CVR was adopted that used eight low-inductance microresistors coupled in parallel and mounted on a BNC connector as in Fig. 4(b).

\section{High-voltage fast spark-gap}

The output of the PFL is connected either directly to a load or to the POS by means of switch S2 of Fig. 1. This is a self-breaking high-voltage fast spark-gap, made from a pair of $60 \mathrm{~mm}$ diameter bead-blasted brass hemispheres with about $5 \mathrm{~mm}$ separation, securely mounted on polyethylene supports The switch operates in high-pressure $\mathrm{SF}_{6}$, has a linear voltage-pressure characteristic over the range used during the tests (i.e., $250 \mathrm{kV}$ at 28 psi to $300 \mathrm{kV}$ at $35 \mathrm{psi}$ ) and an excellent closing voltage reproducibility.

\section{Tesla-PFL generator performance}

Figure 5 shows the output voltage of the PFL during charging, together with the voltage and current delivered to a fixed low-inductance (approximately $55 \mathrm{nH}$ ) load, following

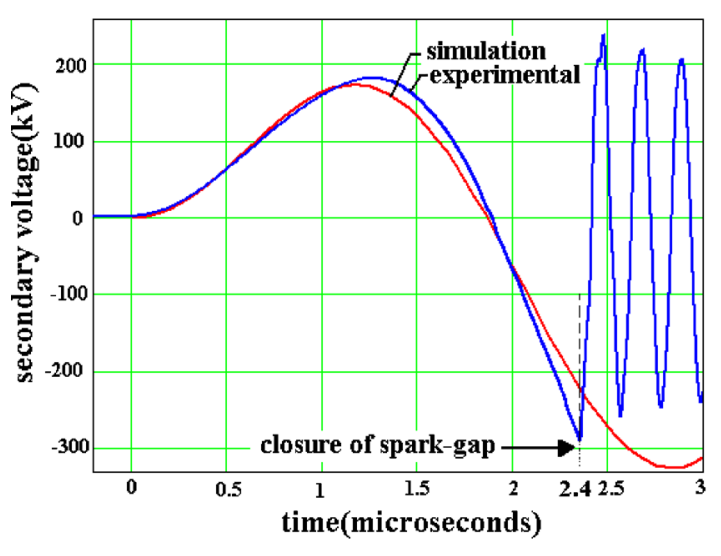

a)

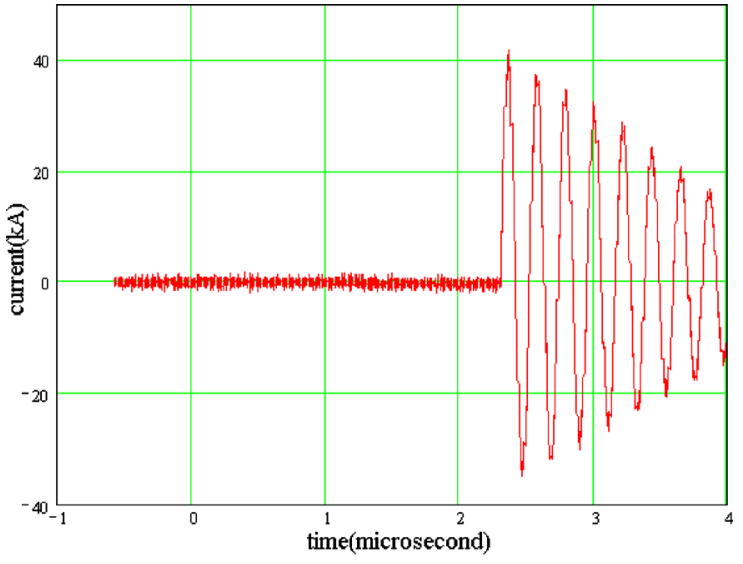

b)

FIG. 5. (Color online) PFL charging and discharging, with S2 spark-gap closing at $-300 \mathrm{kV}$ (a) experimentally recorded PFL output voltage, compared with theoretical prediction up to the moment spark-gap S2 closes. (b) Load current generated by PFL time origin from S1 closure. 


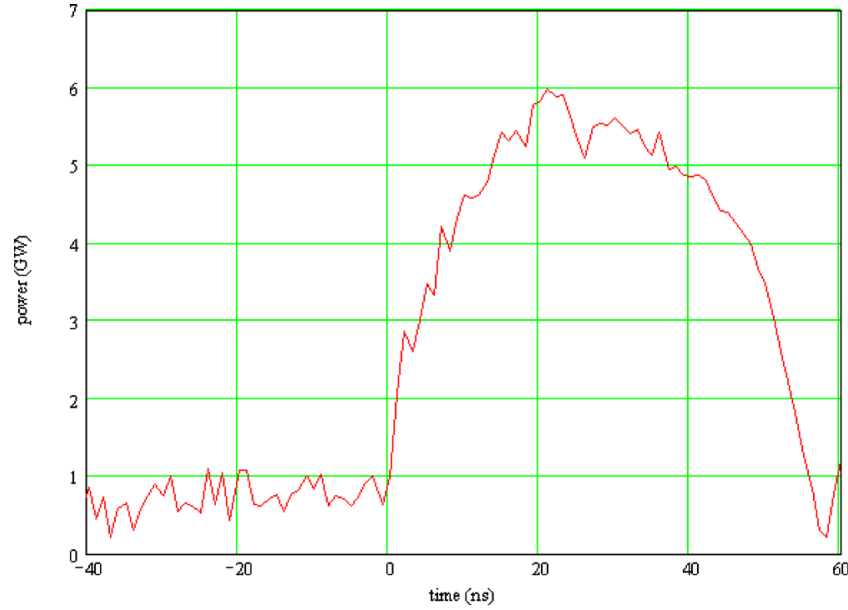

FIG. 6. (Color online) Power delivered to load by the PFL time origin from S2 closure.

closure of switch S2. The load power delivered in these experiments (with no POS present) reaches about $6 \mathrm{GW}$ (Fig. 6), with the line charged to $300 \mathrm{kV}$, although higher values were obtained in one-off shots during the long experimental program.

\section{TESLA-PFL-POS GENERATOR}

\section{A. Plasma opening switch}

In the final phase of the generator development program, a POS was attached to the PFL output to provide a second

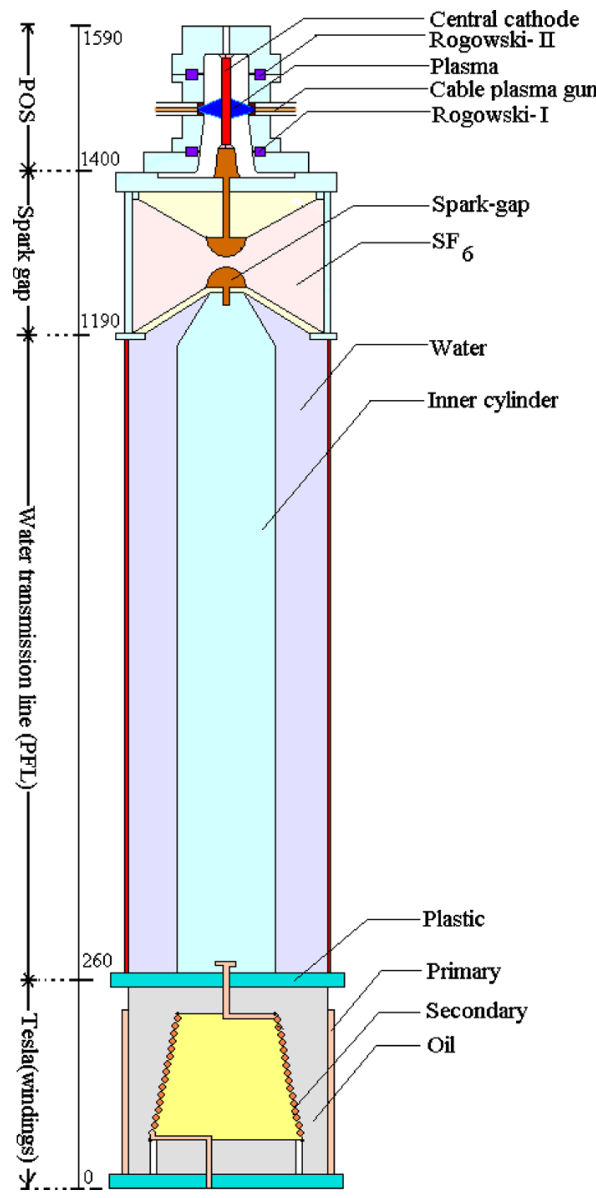

FIG. 7. (Color online) Complete Tesla-PFL-POS generator schematic (dimensions in millimeter).

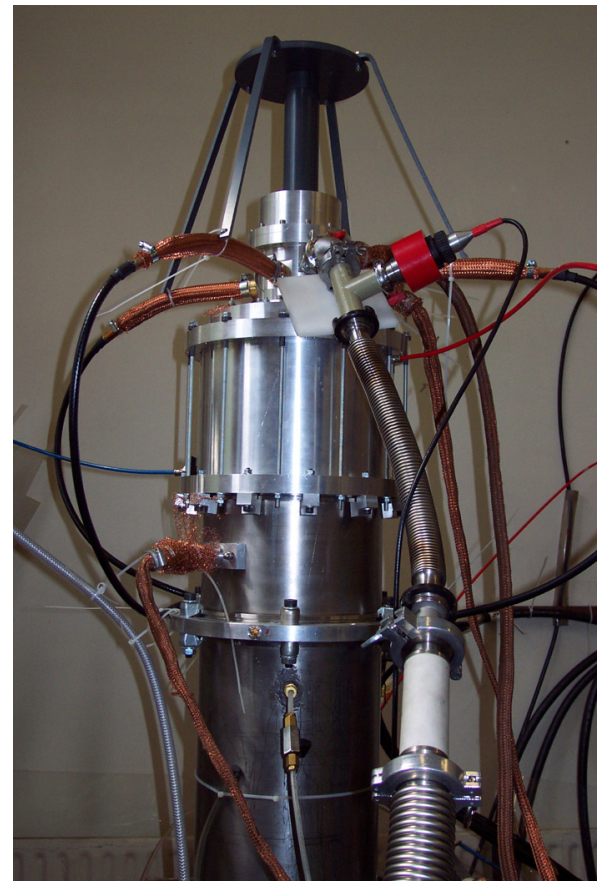

FIG. 8. (Color online) POS assembly mounted on top of PFL.

output conditioning stage. Figure 7 is a schematic of the complete system and Fig. 8 shows the POS mounted on top of the Tesla-PFL generator. The POS has cylindrical geometry with four equally spaced and identical plasma gun injectors (see Figs. 8 and 9) and a small radius cathode $\left(r_{c}\right.$ $=6.5 \mathrm{~mm}$ ) to allow magnetic insulation in a vacuum maintained at $5 \times 10^{-4}$ Torr. The power source for the four plasma gun system is shown in Fig. 10(a) and comprises a single $1 \mu \mathrm{F}$ capacitor (GAEP type 31158) (Ref. 9) charged to $30 \mathrm{kV}$ and a closing switch S3, using the same combination of trigatron and trigger generator as S1 of Fig. 1. Synchronization between the Tesla-PFL generator and the POS plasma guns (i.e., between the firing of $\mathrm{S} 1$ and S3) is achieved by a multidelay pulse generator unit.

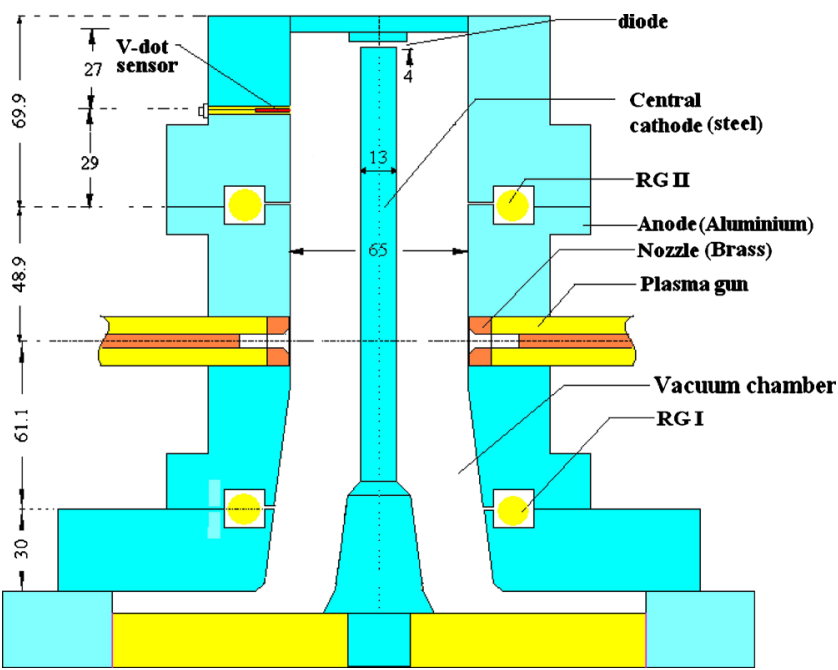

FIG. 9. (Color online) Vacuum chamber schematic containing the POS with its four plasma guns and the diode. Positions of the two Rogowski coils (RGI and RGII) and of the V-dot sensor are also shown (dimensions in millimeter). 


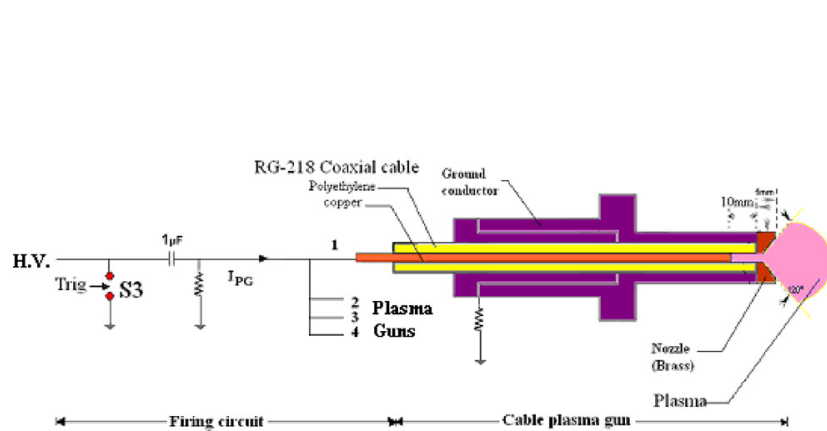

a)

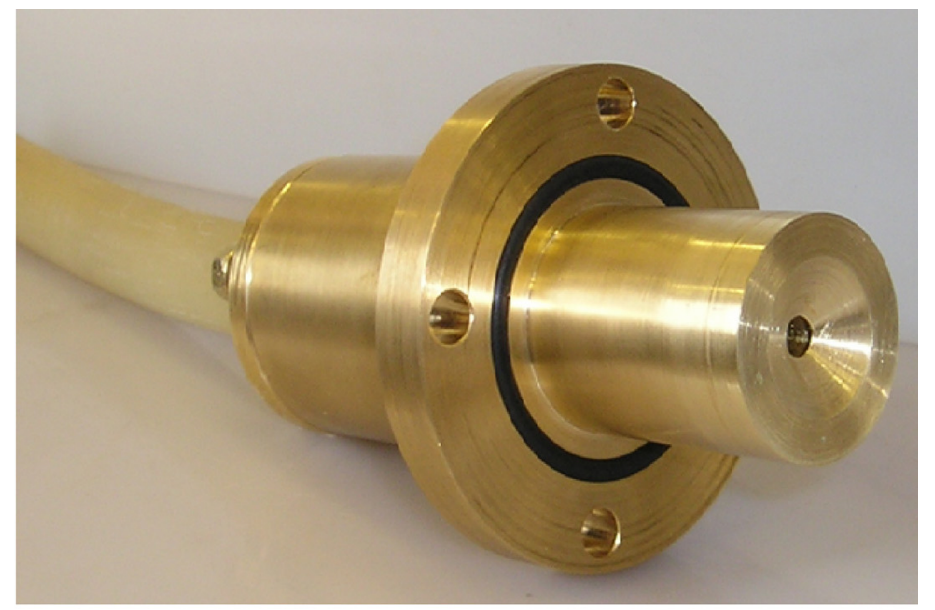

b)

FIG. 10. (Color online) Cable plasma gun (a) electrical power circuit and schematic (b) assembled for mounting inside POS.

\section{B. Plasma guns and plasma characterization using Faraday cups}

The design of the cable-type plasma gun is presented in Fig. 10(b) and the ion plasma emitted, shown previously in spectroscopic studies ${ }^{14}$ to be a mixture of $\mathrm{H}^{+}$(protons), $\mathrm{C}^{+}$, and $\mathrm{C}^{++}$with traces of $\mathrm{Cu}^{+}$, was investigated using both Faraday cups (Fig. 11) and an ultrahigh-speed camera. The latter technique is capable of only detecting carbon plasma and the results, presented in Ref. 15, were useful in determining the optimum design for the plasma gun nozzle. The same study also established that the optical characteristics of the plasma are highly reproducible from shot to shot. Using optical data it was concluded that a time-delay of more than $1.4 \mu \mathrm{s}$ would be required between S1 and S3 should the POS be operated with carbon ions but, as shown below, this could not be achieved in practice.

In what follows, results obtained using Faraday cups are presented. The electrical circuit of a Faraday cup is given in Fig. 11 and an analysis of its typical characteristics has been reported previously. ${ }^{16}$ Using Faraday cups mounted inside a vacuum bell-jar [Fig. 12(a)] and positioned at the various locations, indicated in Fig. 12(b), the carbon plasma charac- teristics were obtained. For each location, the biasing voltage of Fig. 11 was maintained just below the value at which an electrical breakdown was observed by the signal from the cup displaying a sudden excursion to a very high value. In this way, only electrons with very high velocities could reach the interior of the cups and their perturbing effect is confined to the first few tens of nanoseconds. The biasing voltage was between $-100 \mathrm{~V}$ for the closest cup locations (i.e., 25-50 $\mathrm{mm}$ ) and $-200 \mathrm{~V}$ for those most remote (approximately 200 $\mathrm{mm}$ ). The value of the resistor $R_{\mathrm{fc}}$ was chosen to provide a convenient voltage peak $\mathrm{V}_{\mathrm{fc}}$ for measurement by an oscilloscope (Fig. 11). Taking into account that the optical study revealed a highly reproducible plasma, the carbon ion velocity $v_{\mathrm{C}}$ was obtained from a probe successively positioned along the gun axis [at locations A, B, C, and D of Fig. 12(b)] as the ratio of the axial distance between two positions and the corresponding time delay between their voltage peaks [Fig. 13(a)]. To cross-check the results, experiments using two cups, positioned as in Fig. 12(c), were performed [Fig. 13(b)]. The carbon velocity given in Table I represents a median value. Once the velocity is determined, and the current peak detected by the Faraday cup $I_{f c}=V_{f c} / R_{f c}$ is known,

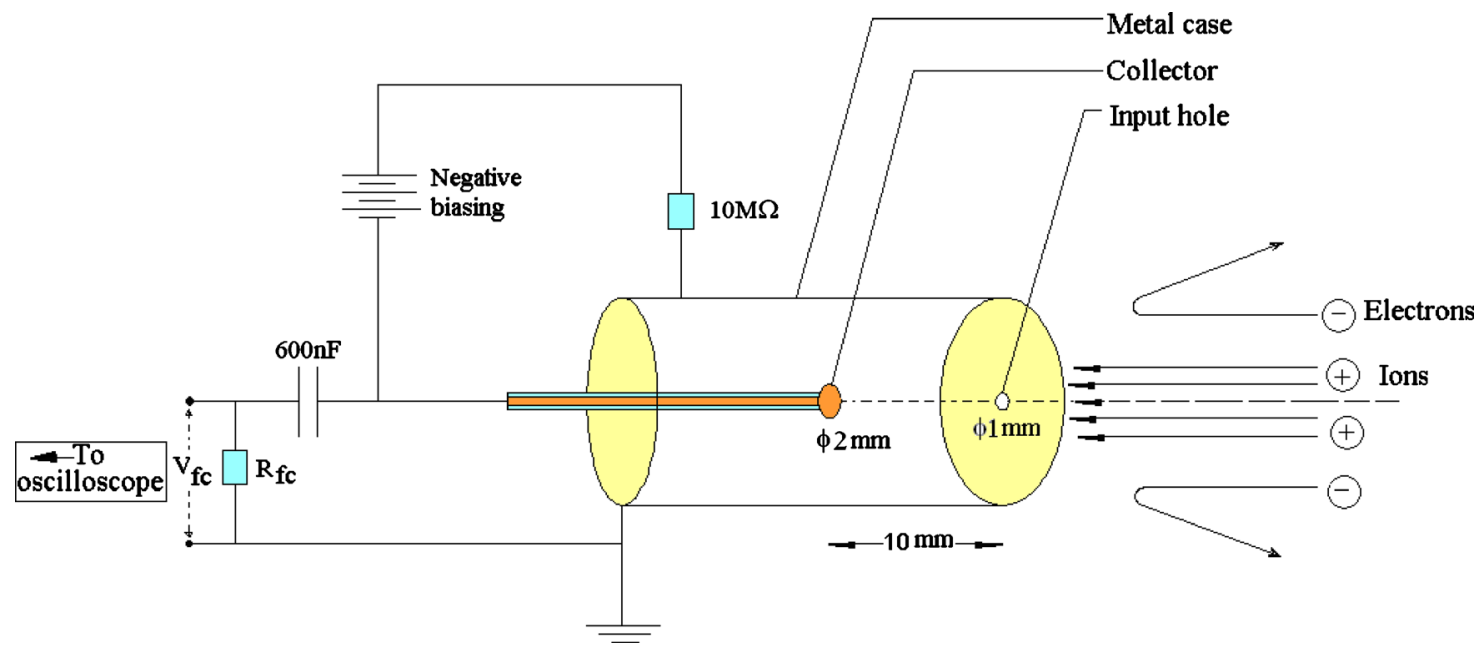

FIG. 11. (Color online) Electrical scheme of a Faraday cup. 

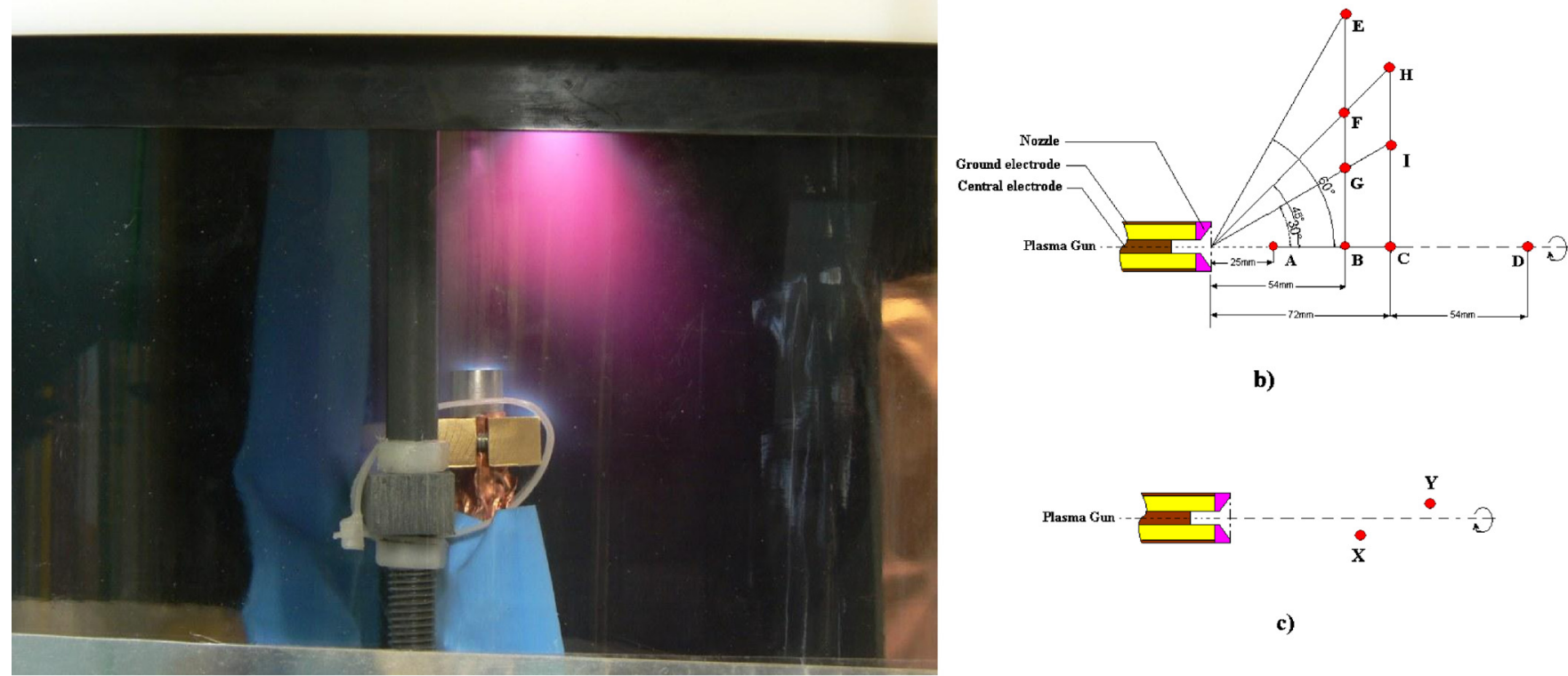

b)

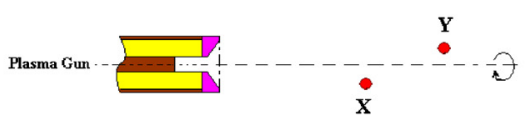

c)

a)

FIG. 12. (Color online) Plasma gun studies. (a) Faraday cup mounted inside the vacuum bell-jar and under ion bombardment during the studies. Various locations (not to scale) for the Faraday cup. (b) Locations for the study using one cup, with A, B, C, and D along the plasma gun axis and (c) locations for a pair of cups.

the carbon density $\mathrm{n}_{\mathrm{C}}$ can be estimated from $\mathrm{n}_{\mathrm{C}}$ $=\mathrm{I}_{\mathrm{fc}} / \mathrm{S}_{\mathrm{fc}} v_{\mathrm{C}} \mathrm{Ze}$, where $\mathrm{S}_{\mathrm{fc}}$ is the input hole area $(1 \mathrm{~mm}$ in diameter), $\mathrm{Z}$ is the carbon ionization state, and e is the electron charge. An important finding was that the densities calculated from data provided by the cups at locations $\mathrm{G}$ and I are much smaller than those at locations $\mathrm{B}$ and $\mathrm{C}$, suggesting that the plasma distribution along a line perpendicular to the gun axis (i.e., along the POS cathode) falls by approximately e-times at the border of a region defined by an angle of $30^{\circ}$.
This was helpful in estimating the POS active plasma length $l$ (a parameter used in the calculations below) as $30 \mathrm{~mm}$.

Unfortunately, due to its very high value, the $\mathrm{H}^{+}$plasma velocity could not be accurately determined using the above technique. It was therefore necessary to assume that, due to the similar way in which different ions are accelerated in the gun, their kinetic energies are almost equal, so that $v_{\mathrm{H}}$ $\approx v_{\mathrm{C}} \sqrt{\mathrm{m}_{\mathrm{C}} / \mathrm{m}_{\mathrm{H}}}$, where $\mathrm{m}$ and $v$ are the ion mass and velocity

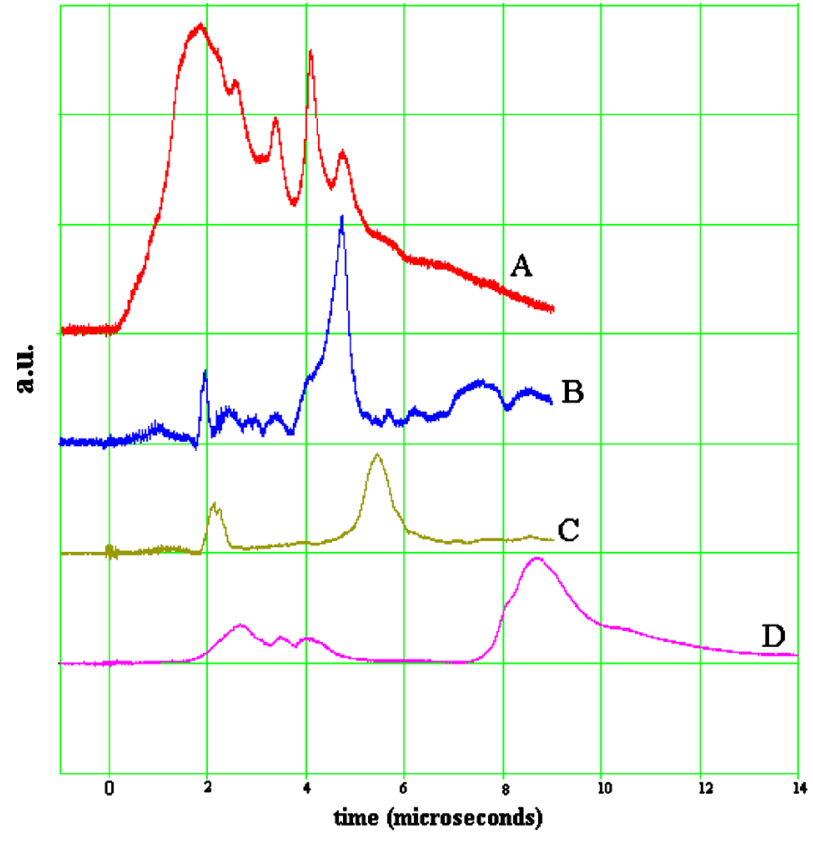

a)

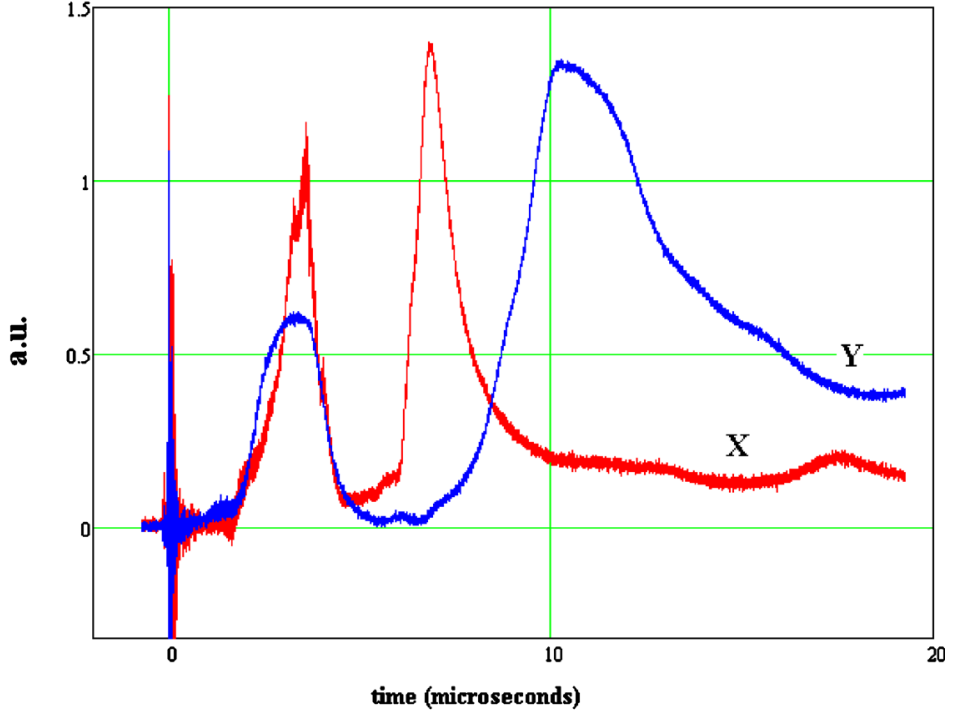

b)

FIG. 13. (Color online) Faraday cup signals: (a) corresponding to positions (A, B, C, and D) along the gun axis as indicated in (a). (b) Corresponding to positions $\mathrm{X}$ and $\mathrm{Y}$ indicated in (b). Time origin from S3 closure. 
TABLE I. Carbon and hydrogen plasma parameters.

\begin{tabular}{|c|c|c|c|}
\hline \multicolumn{2}{|c|}{$\begin{array}{l}\text { Ion drift velocity } v_{d} \\
(\mathrm{~cm} / \mu \mathrm{s})\end{array}$} & \multicolumn{2}{|c|}{$\begin{array}{l}\text { Ion density } \mathrm{n}_{\mathrm{i}} \\
\left(10^{19} \mathrm{~m}^{-3}\right)^{\mathrm{a}}\end{array}$} \\
\hline Carbon ions & Hydrogen ions & Carbon ions & Hydrogen ions \\
\hline 2.29 & 7.93 & 6 & 1.84 \\
\hline
\end{tabular}

${ }^{\mathrm{a}}$ The density is calculated for a position along the plasma gun axis corresponding to the POS cathode surface.

and the subscripts are $\mathrm{H}$ and $\mathrm{C}$ are for hydrogen and carbon. The approximate characteristics of the $\mathrm{H}^{+}$plasma thus obtained are also provided in Table I.

To investigate the influence of the above findings on the POS operation, a model of its plasma dynamics is needed. This requires in principle results from a complex 2D plasma code but, for a qualitative discussion and due to the relatively fast rise time of the input current of about $50 \mathrm{~ns}$, the simple POS erosion model developed by NRL (Ref. 3) was adopted, which completely ignores magnetic pressure and its influence on plasma dynamics. According to this simple model, the predicted bipolar threshold current $\mathrm{I}_{\mathrm{BP}}$ at which the POS starts to open is given by $\mathrm{I}_{\mathrm{BP}}=\mathrm{n}_{\mathrm{i}} \mathrm{Ze} v_{d}\left(2 \pi \mathrm{r}_{\mathrm{c}} l\right) \sqrt{\mathrm{m}_{\mathrm{i}} / \mathrm{Zm}_{\mathrm{e}}}$, where subscripts $\mathrm{i}$ and $\mathrm{e}$ are for ion and electron and $v_{d}$ is the ion drift velocity. Introducing the data from Table I corresponding to $\mathrm{C}^{++}$ions $(\mathrm{Z}=2)$ gives the threshold opening current as approximately $57 \mathrm{kA}$. A similar calculation predicts that a POS operating with $\mathrm{H}^{+}$plasma will begin to open at about 12 kA. As the input peak current produced by the Tesla-PFL generator is limited to less than $40 \mathrm{kA}$, it is expected that the present POS will only be capable of operating with a proton plasma. For operating the POS in this mode, and as indicated by signals in Fig. 18, the required time-delay between firing the Tesla-PFL generator and the plasma gun power source is practically zero. The POS experiments fully confirmed these qualitative findings, with all successful shots presented below being achieved with practically no time-delay between S1 and S3. Although many attempts have been made, the POS has never opened when the time-delay was increased, i.e., it could not be operated with a carbon plasma. Figure 14

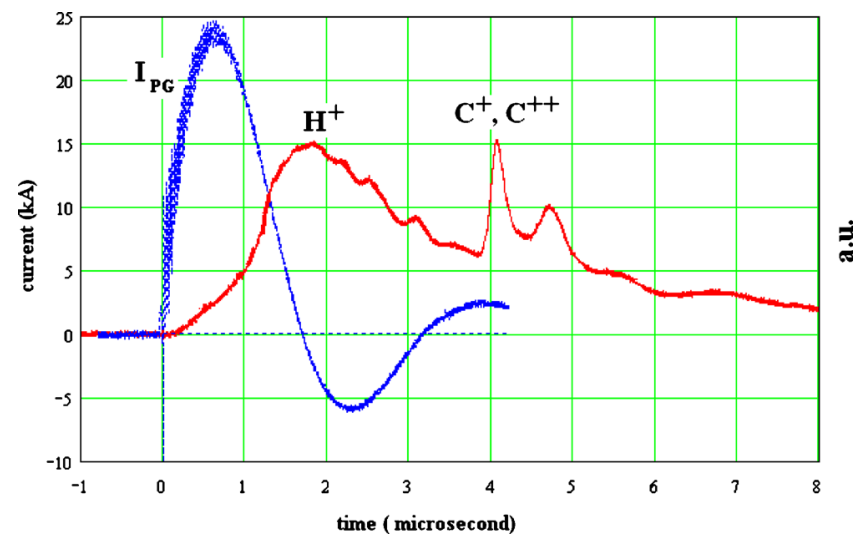

FIG. 14. (Color online) Faraday cup signal (in arbitrary units) showing the peaks corresponding to the main ion species emitted by the plasma gun. Measurement performed at a position corresponding to the POS cathode surface. The plasma gun current $\mathrm{I}_{\mathrm{PG}}$ (in $\mathrm{kA}$ ) is also shown, helping in the determination of the required time delays between firing S1 and S3 corresponding to the various ion species. Time origin from S3 closure.

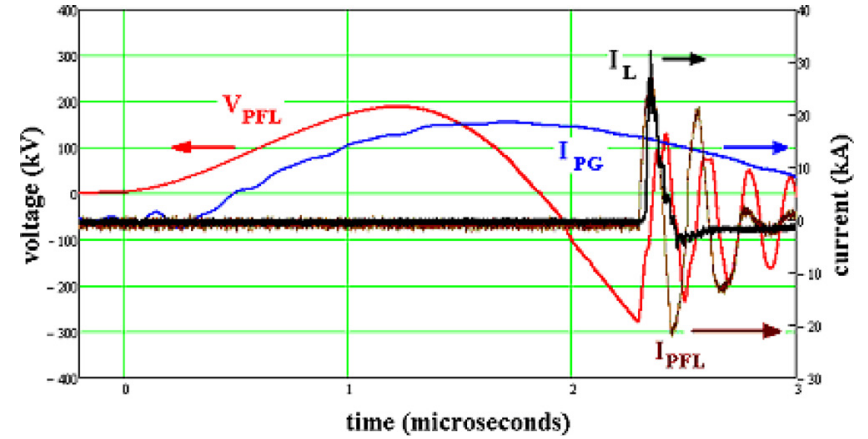

FIG. 15. (Color online) Complete system operated with a low-inductance load. Note that both the Tesla-PFL generator (S1) and the plasma gun power source (S3) start at about the same time. The various currents in the system are shown, together with the voltage across PFL. Time origin from S1 closure.

shows the time delays between closure of S3 and the generation of the various ion species at a distance corresponding to the POS cathode surface.

\section{Results with the complete Tesla-PFL-POS generator}

The time history of the most important currents and voltages during a POS shot is presented in Fig. 15, which also gives an indication of the synchronization between the Tesla transformer circuit (switch S1) and the plasma gun circuit (switch S3). The results in Fig. 16(a) are for a fixed lowinductance load of approximately $24 \mathrm{nH}$ and demonstrate a compression in the rise time of the current of almost five. The theoretical prediction in Fig. 16(b), based on the simple NRL model, ${ }^{3}$ shows very good correspondence with experimental data, but only during the first phase of the switch opening, termed "normal" erosion. Later the calculations become much more optimistic, with the predicted current rise time of 5.4 ns being only about one-half the experimental value of $11 \mathrm{~ns}$. This is probably due to the model neglecting the actual complex axial dynamics of the plasma.

The results in Fig. 17 are obtained with a dynamic load, i.e., a simple diode made from two metallic cylinders having their parallel and flat end surfaces separated by $4 \mathrm{~mm}$ and mounted as shown in Fig. 9. The POS action changes the characteristics of the load current, from a peak of about 5.5 $\mathrm{kA}$ and a rise time of approximately $95 \mathrm{~ns}$ to a peak of about $30 \mathrm{kA}$ and a rise time of approximately $5 \mathrm{~ns}$, showing clearly considerable power amplification. To determine the power delivered to the dynamic load, either the time-dependence of the load impedance or of the voltage across the load must be known. A 2D numerical modeling is best for this purpose but this was outside the aims of the present program. For a very rough estimate, using the Child-Langmuir Law for spacecharge limited flow in plane geometry, ${ }^{17}$ and for a current in excess of $20 \mathrm{kA}$, a corresponding voltage in excess of $1 \mathrm{MV}$ is predicted. On the other hand, the measurement of voltage across the load using the V-dot sensor of Fig. 9 proved to be very difficult, due to extremely powerful disturbances. Only by protecting the probe tip with a layer of epoxy and reducing the level of the load current (thus diminishing the load power) could a meaningful result be obtained, as in Fig. 18. 


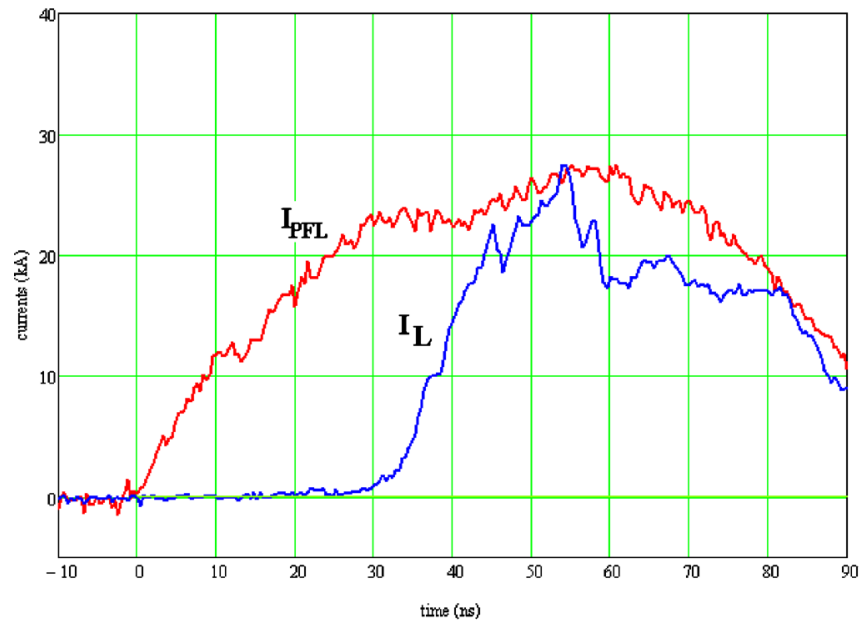

a)

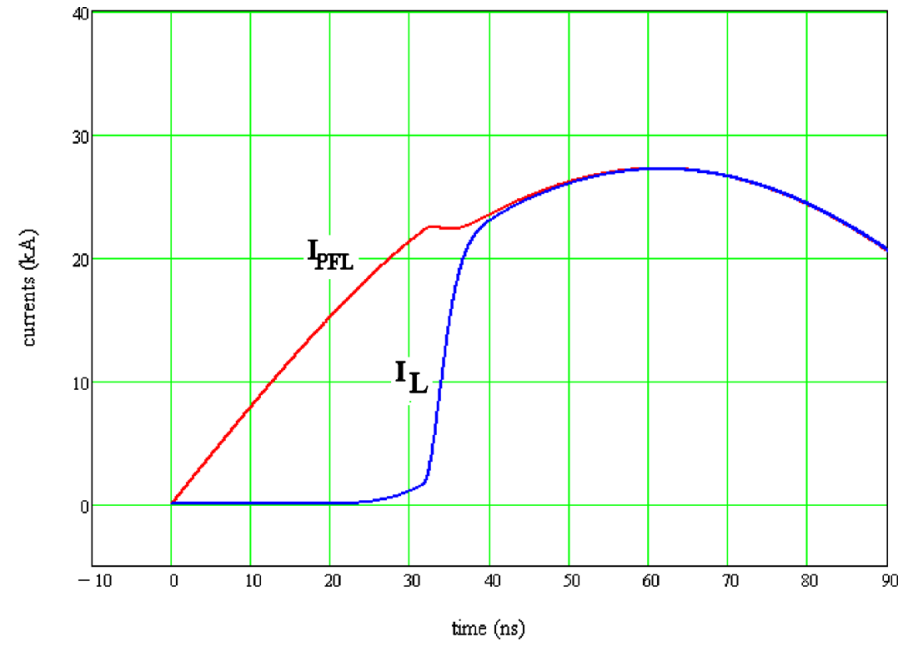

b)

FIG. 16. (Color online) (a) POS result obtained with a low-inductance load. The two currents, downstream $\left(\mathrm{I}_{\mathrm{PFL}}\right)$ and upstream $\left(\mathrm{I}_{\mathrm{L}}\right)$, are measured with two identical Rogowski coils. The time compression obtained with the POS activated is from a rise time of about 52 ns down to about $11 \mathrm{~ns}$. Time origin from S2 closure. (b) Predictions using the simple NRL "erosion" model (Ref. 3).

Even then the total power delivered to the dynamic load exceeded $10 \mathrm{GW}$, illustrating well the considerable potential of the system.

\section{CONCLUSIONS}

The first stage of a Loughborough research program, with the final aim of demonstrating a table-top repetitive system with an output greater than $10 \mathrm{GW}$, has been successfully completed. A powerful $300 \mathrm{kV}$ Tesla-charged PFL pulsed power generator has been built and operated successfully with a high degree of reproducibility for more than two years. A series of current and voltage sensors has been developed, calibrated, and implemented and the whole system proved to be of great use in training students in the art and science of pulsed power physics and technology.

Plasma emitted by cable guns has been studied using both Faraday cups and a high-speed camera. The results have

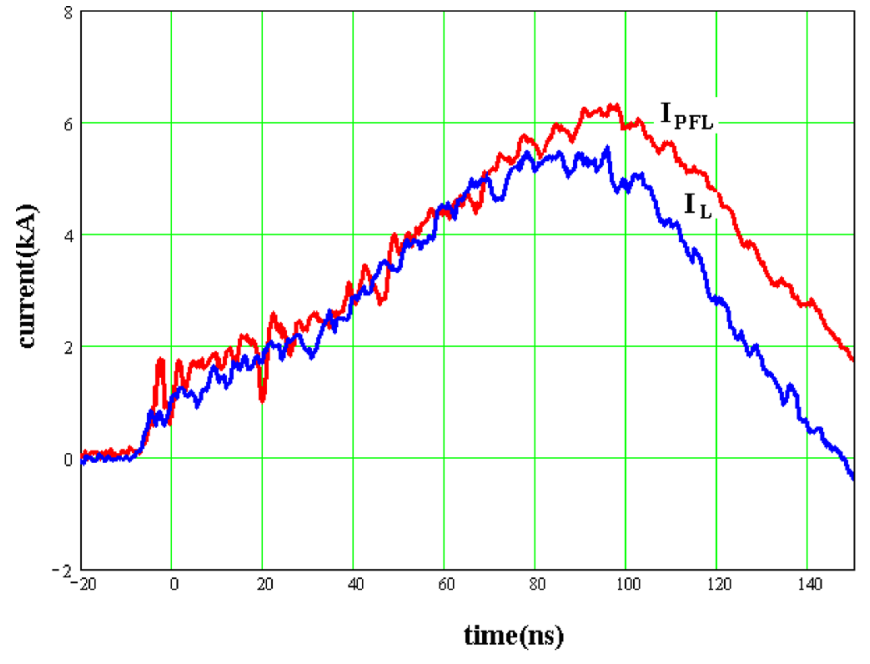

a) shown that both protons and carbon ions are emitted and some of their characteristics, such as velocity and density, have been determined. Simple estimates based on these data suggest that the level of current required by the POS to open, when operated with carbon ions, is much larger than the Tesla-PFL generator can actually provide. This rather speculative initial conclusion was later fully proved in practice when the POS was successfully operated, but using only protons. Tests with the miniature POS demonstrated that a power in excess of $10 \mathrm{GW}$ can be delivered to a dynamic load with an impedance probably in the region of a few tens of ohms.

Summarizing, the most important technological novelties are seen in the successful demonstration of one of the smallest POS ever reported, capable of producing a voltage close to $1 \mathrm{MV}$ in a $\mathrm{cm}$ size volume and, to the best of authors' knowledge, the first reported POS functioning with

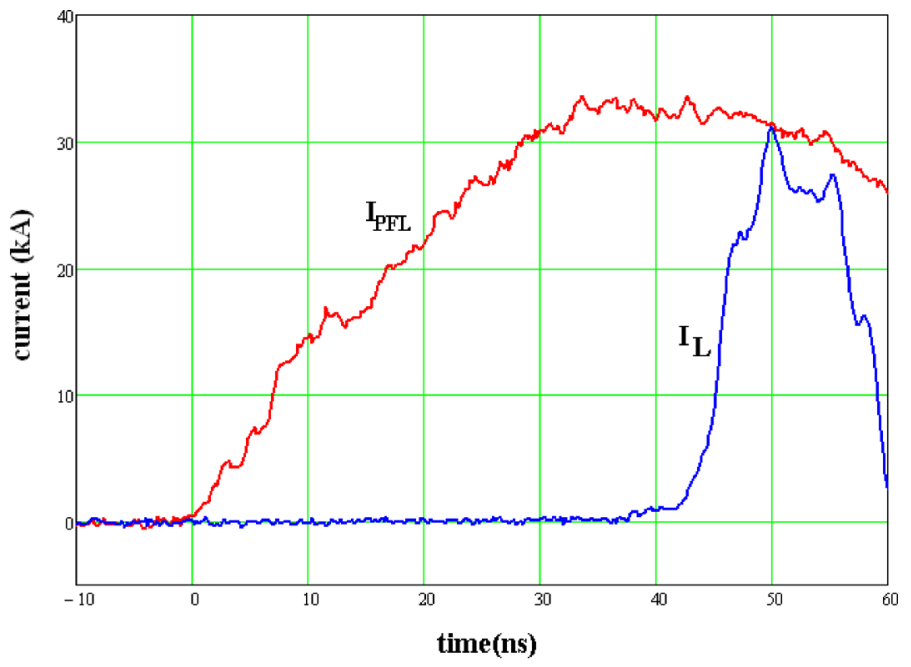

b)

FIG. 17. (Color online) Time dependence of PFL output current $\mathrm{I}_{\mathrm{PFL}}$ and load current $\mathrm{I}_{\mathrm{L}}$ with a dynamic load (diode) attached: (a) without POS and (b) with POS activated. Time origin from S2 closure. 


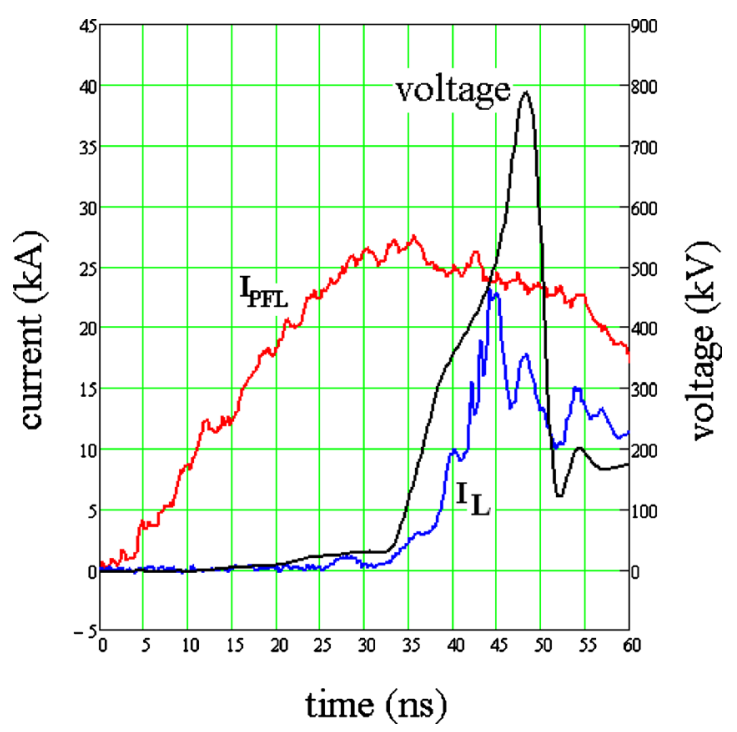

FIG. 18. (Color online) Experimental results obtained with the complete generator attached to a diode. POS input current $\left(\mathrm{I}_{\mathrm{PFL}}\right)$, load current $\left(\mathrm{I}_{\mathrm{L}}\right)$, and load voltage are all presented. Load power is in excess of $10 \mathrm{GW}$. Time origin from S2 closure.

pure proton plasma. This last property brings an advantage over previous conventional POS machines for which, because the plasma is a mixture of a number of carbon species each with a different threshold opening current, the opening time is clearly increased.

The results open the way for designing a table-top, repetitive $15 \mathrm{GW}$ generator based on a miniature POS coupled to a Blumlein PFL charged by a Tesla transformer. The Blumlein PFL will be constructed using HV cable technology which will allow a very compact system design.

${ }^{1}$ P. Sarkar, S. W. Braidwood, I. R. Smith, B. M. Novac, R. A. Miller, and R. M. Craven, IEEE Trans. Plasma Sci. 34, 1832 (2006).

${ }^{2}$ B. M. Novac, P. Sarkar, I. R. Smith, and C. Greenwood, Proceedings of the 16th IEEE International Pulsed Power Conference, Washington, D.C., 2009, Paper No. O2P-61.

${ }^{3}$ B. W. Weber, R. J. Commisso, G. Cooperstein, J. H. Grossman, D. D. Hinshelwood, D. Mosher, J. M. Neri, P. F. Ottinger, and S. J. Stephanakis, IEEE Trans. Plasma Sci. 15, 635 (1987).

${ }^{4}$ P. F. Ottinger, S. A. Goldstein, and R. A. Meyer, J. Appl. Phys. 56, 774 (1984).

${ }^{5}$ P. Sarkar, B. M. Novac, I. R. Smith, and G. Louverdis, Proceedings of the 28th Int. Power Modulator Symp., Las Vegas, NV, 2008, pp. 268-271.

${ }^{6}$ J. Luo, B. M. Novac, I. R. Smith, and J. Brown, J. Phys. D 38, 955 (2005).

${ }^{7}$ S. V. Ansoft Maxwell, http://www.ansoft.com/maxwellsv/, accessed January 2010.

${ }^{8}$ Q. Yu and T. W. Holmes, IEEE Trans. Electron. Comput. 43, 88 (2001).

${ }^{9}$ GAEP, http://www.gaep.com/, accessed January 2010.

${ }^{10}$ L3 Pulse Sciences, http://pulsesciences.com/, accessed January 2010.

${ }^{11}$ C. A. Ekdahl, Rev. Sci. Instrum. 51, 1645 (1980).

${ }^{12}$ D. G. Pellinen, M. S. DiCapua, S. E. Sampayan, H. Gerbracht, and M. Wang, Rev. Sci. Instrum. 51, 1535 (1980).

${ }^{13}$ D. Pellinen, Rev. Sci. Instrum. 42, 667 (1971).

${ }^{14}$ F. Douieb, Ph.D. thesis, Universite de Paris XI, Orsay, 1995.

${ }^{15}$ R. Kumar, B. M. Novac, I. R. Smith, and C. Greenwood, IEEE Trans. Plasma Sci. 36, 1266 (2008).

${ }^{16}$ S. Neff, S. Wright, C. Plechaty, J. Ford, R. Royle, and R. Presura, Proceedings of the 16th IEEE Int. Pulsed Power Conference, Albuquerque, NM, 2007, pp. 1288-1291.

${ }^{17}$ W. Rix, D. Parks, J. Shannon, J. Thompson, and E. Waisman, IEEE Trans. Plasma Sci. 19, 400 (1991). 